\title{
Avaria by the bottom of a bolt on a diesel of engine
}

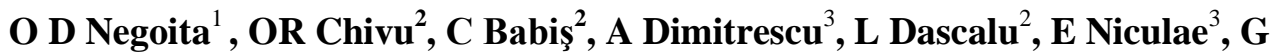 \\ Iacobescu $^{2}$, A Semenescu ${ }^{4}$, and A Purcarea ${ }^{1}$ \\ ${ }^{1}$ Faculty of Entrepreneurship, Business Engineering and Management, Politehnica University \\ of Bucharest, Romania \\ ${ }^{2}$ Welding and Material Technology Department, Politehnica University of Bucharest, Romania \\ ${ }^{3}$ Theory of Mechanisms and Robots Department, Politehnica University of Bucharest, \\ Romania \\ ${ }^{4}$ Economics Engineering Department, Politehnica University of Bucharest, Romania, \\ virlan_oana@yahoo.co.uk
}

\begin{abstract}
A drive from a diesel engine of a truck was broken into four parts during normal use. Damaged bolt caused longitudinal and transverse cracks. They started from the surface of the hole and stretched outward. The appearance of marginal signs and striations on the surfaces of all regions of origin of the crack indicate that fatigue breakage is the dominant damaging mechanism of the bolt. The surface of the hole and the outer surface are indicated to be cemented. Microstructure and microstructure profiles at the bolt surface and in the regions of the hole surface were examined to determine the thickness of the cementitious layer. However, not only there was no cementitious layer found on the surface of the hole, but also a serious decarburization occurred in the area. The appearance of decaying the surface of the hole greatly decreases the fatigue strength of this area, so the crack has started from the surface of the hole and stretched to the outer circle, eventually opening the tear. Inappropriate cementing technology is responsible for decarburation of the surface of the hole.
\end{abstract}

Keywords: bolt, fatigue break, longitudinal and transverse cracks

\section{Introduction}

Diesel engines have a widespread worldwide use, which is why some words about their operation are needed. Compressing a gas leads to an increase in its temperature, this being the method by which fuel is fired in diesel engines. Air is sucked into cylinders and is compressed by the piston up to a 25: 1 ratio, higher than that of spark ignition engines. Towards the end of the compression stroke the fuel (fuel) is sprayed into the combustion chamber by means of an injector. Diesel ignites when the air is already heated by compression to a temperature of about $700-900^{\circ} \mathrm{C}$. Fuel combustion results in increased temperature and pressure acting on the piston. Next, as with regular motors, the force transmits the piston force to the crankshaft, transforming the linear motion into rotation. Aspiration of the air in the cylinders is done by means of the valves, arranged at the cylinder head. To increase power, most modern diesel engines are supercharged in order to increase the amount of air introduced into the cylinders. The use of an intermediate cooler for the air introduced into the cylinders increases the air density and leads to a better yield.

In winter, when cold outside, diesel engines start harder because the massive massive mass of the engine block (cylinder and cylinder head) absorbs much of the heat produced by compression, reducing the temperature and preventing ignition. Some diesel engines use electric heaters, such as 
incandescent glow plugs, to help fuel diesel when the diesel engine starts. Other motors use electrical resistors arranged in the intake manifold to heat the air. Electrical resistors mounted in the engine block are also used to ease starting and reduce wear. Diesel has a high degree of viscosity, especially at low temperatures, leading to the formation of crystals in the fuel, especially in the filters, thus preventing proper engine.

Mounting small electrical devices to heat diesel, especially in the tank and filter area, has solved this problem. The injection system of many engines also sends the already heated, non-injected diesel fuel tank back into the tank to prevent crystallization of fuel from the tank. Nowadays, the use of modern additives has solved this problem as well. A vital component of diesel engines is the mechanical or electronic speed controller that regulates engine speed by correctly dosing injected diesel. Unlike spark ignition engines (Otto), the amount of suction air is not controlled, which leads to over-engineing. Mechanical regulators use different mechanisms depending on load and speed. Electronically controlled, modern engine controllers command fuel injection and limit engine speed through a central control unit that receives permanent signals from the sensors, accurately metering the injected amount of diesel.

Accurate control of injection times is the secret to reducing fuel consumption and pollutant emissions. The injection times are measured in the crankshaft rotational angles before the upper dead point. For example, if the central control unit initiates the injection 10 degrees before the higher dead point, we talk about a 10-degree injection advance. The optimal injection advance is given by the construction, speed and load of the engine.

By advancing the injection time (the injection takes place before the piston reaches the dead end), the combustion is complete, at high pressure and temperature, but also increases the emissions of nitrogen oxides. At the other extreme, a delayed injection leads to incomplete combustion and visible particulate emissions.

The modern diesel engine is a combination of the creations of two inventors. In general, it remains true to Rudolf Diesel's original concept, that is, the fuel is ignited by compressing air from the cylinder. But almost all diesel engines today use the so-called solid injection system, invented by Herbert Akroyd Stuart, for its incandescent head engine (a compression-ignition engine that preceded the diesel engine, but works somewhat differently).

In the case of solid injection, the fuel is brought to extreme pressure by means of pumps and introduced into the combustion chamber by means of injectors and compressed air in an almost solid state. Initially, the fuel was injected into the diesel engine by compressed air that spraying it into the cylinder.

The size of the air compressor was so great that the first diesel engines were very heavy and bulky in relation to the power produced, especially due to the traction of such compressors. The first engines mounted on the ships had an auxiliary engine dedicated to driving the injection compressor. The system was too big and heavy to be used in the automotive industry.

\section{Experimental research}

Experimental research refers to the operation of a diesel engine of a truck, in which a failure occurred during operation. An abnormal sound was emitted by the engine during the truck's journey. The engine was disassembled in the car repair shop. It was discovered that the bolt was crushed in four pieces and that the piston, shirt and bay were also damaged. The accumulated mileage of the engine at the time of the accident is $140.00 \mathrm{~km}$. The defective bolt is made of $20 \mathrm{Cr}$ steel. On the internal and external surfaces, cementation should be done according to the technical

The chemical composition of the defective bolt material was studied by spectroscopic methods. The microstructure of the outer shell of the bolt, the surface of the hole and the base region was studied by electronic scanning microscopy (SEM), an Philips XL-30 electronic microscope and an Olympus GX51 optical microscope.

The microstructure (HRC) of the base material and the outer surface of the defective bolt were measured. The microporous profiles from the surface to the inside in different regions to the outside 
and inside of the bolt were made with a Vikers MH-6 measuring device at a $1000 \mathrm{~g}$ load to determine the depth of the cementitious layer. According to the Chinese standard (GB 9450), when the hardness of the measured position is equal to HV1550, the depth from the HV1550 position to the surface is defined as the depth of the cementitious layer.

The depth of the cementitious layer from the outside and from the inside of the bolt is $0.8-1.2 \mathrm{~mm}$ and more than $0.5 \mathrm{~mm}$ and the depth of the cemented layer inside and outside is less than $2.5 \mathrm{~mm}$. The destroyed surfaces were analyzed by visual observation and SEM observation to study the failure mechanism.

\section{Experimental results \\ $2.1 \quad$ Visual examination}

The fragments were put together for the restoration of the destroyed bolt as seen in Figure 1. The bolt fractured into four fragments labeled 1, 2, 3 and 6 in Figure. 2. To observe the bursting surface, the fragment 3 was carefully opened along the initial direction of crack propagation and separated into three labeled parts 3, 4 and 5, seen in Figures 1 and 2. Matching fragments is shown in Figure 3.

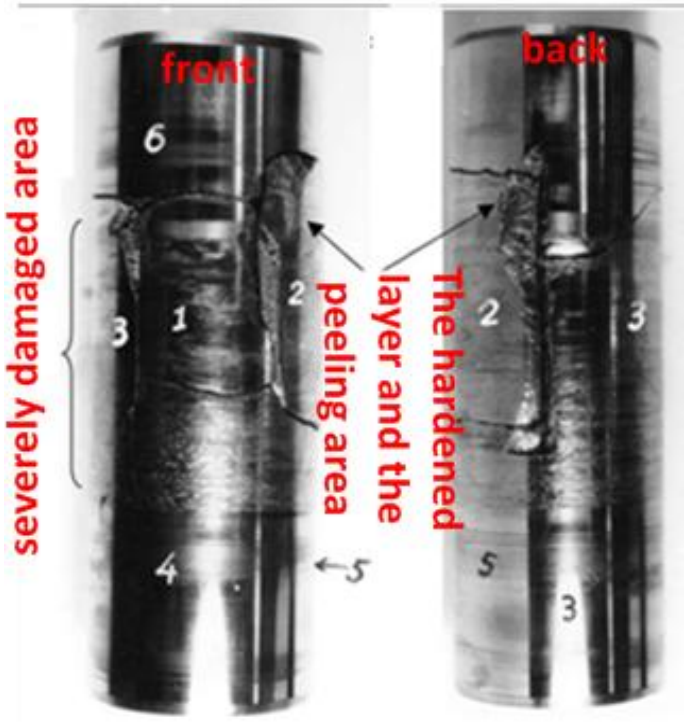

Figure 1. Recovering the broken bolt from fragments

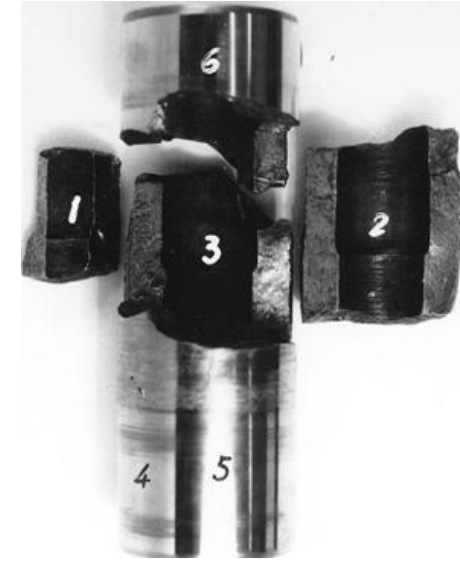

Figure 2. Fragments of the bolt

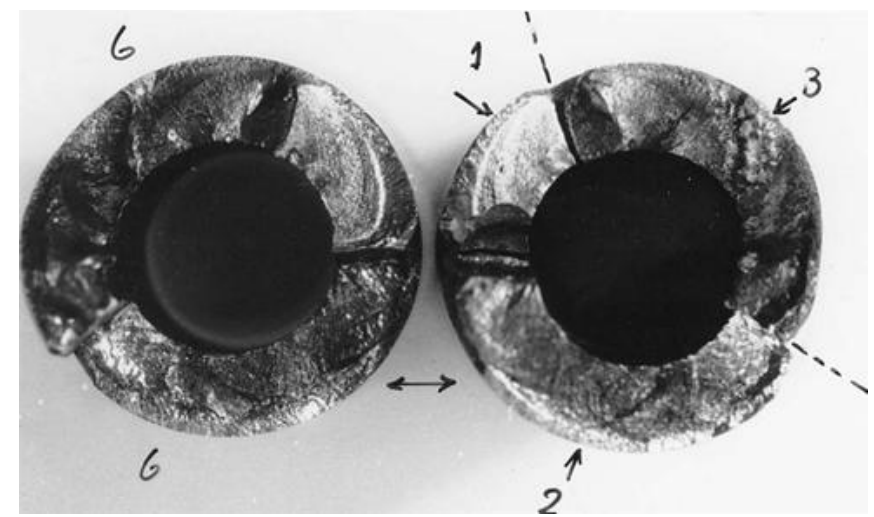

Figure 3. Surface breakage study (crack propagation areas)

All the cracks were initiated inside the hole and propagated outwardly to the bolt. Depending on the degree of wear of the deformation surfaces in different regions, it was established that the initiation 
and propagation sequence of the 11 origins of the crack is as follows: $D, C, G \rightarrow I, K \rightarrow A, B, H \rightarrow$ $\mathrm{E}, \mathrm{F}, \mathrm{J}$.

Observations indicate that the origins of the 11 cracks are located in the outer surface area which has been severely worn out and most of the outer cement layer has been exfoliated in some regions of origin of the fissured fissures in Figure 1 and the areas soaked in the figure 4.

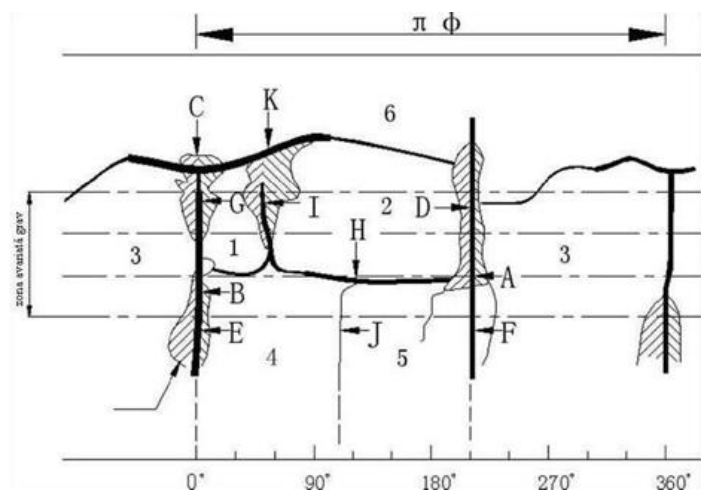

Figure 4. Plain scheme of crack extension

Visual observations on the outer surface indicate that regions with a marked wear of approx. 23 $\mathrm{mm}$, occur at both ends of the bolt and result from the wear produced at the contact between the bolt and the piston shoulders. At the center of the bolt there is a large worn wear area of about $36 \mathrm{~mm}$ in width, produced at the contact between the bolt and the bead.

According to the morphology of wear on the outer surface of the bolt, it can be deduced that the contact load between the bolt and the bolt is higher, but the condition of lubrication is defective in this area.

\subsection{Observation of SEM breakage surfaces}

The morphology of the breaking surfaces in the origin regions of the crack was clearly observed with the SEM. The areas with typical fissure crack propagation striations appear at the origin of cracks $\mathrm{C}$, $\mathrm{H}, \mathrm{K}$ as seen in Figure 5. This suggests that the three cracks with origins in these areas have propagated in the radial direction through fatigue. The fracture areas of the longitudinal crack (G, I, D) have been seriously worn, so that beach marks or fatigue strings can not be clearly seen.

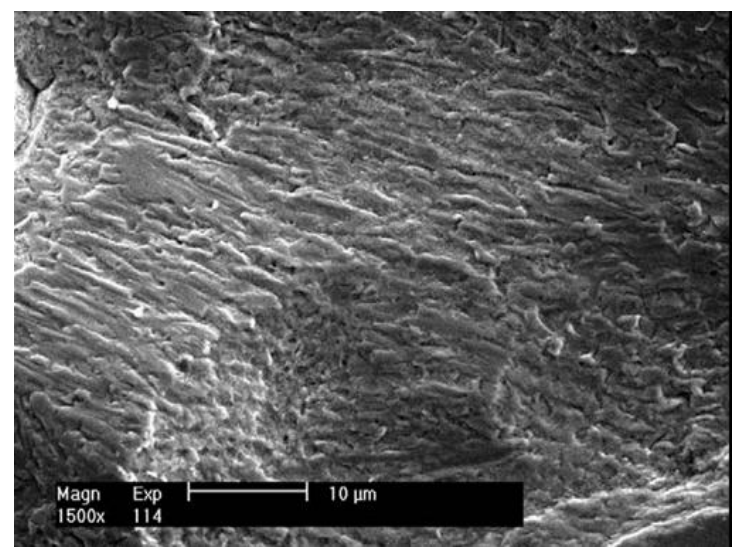

Figure 5. The SEM image of the rupture surface shows fatigue streaks (origin of crack C)

A morphology of intergranular cracking was found on the surface of the outer region as seen in Figure 6. 


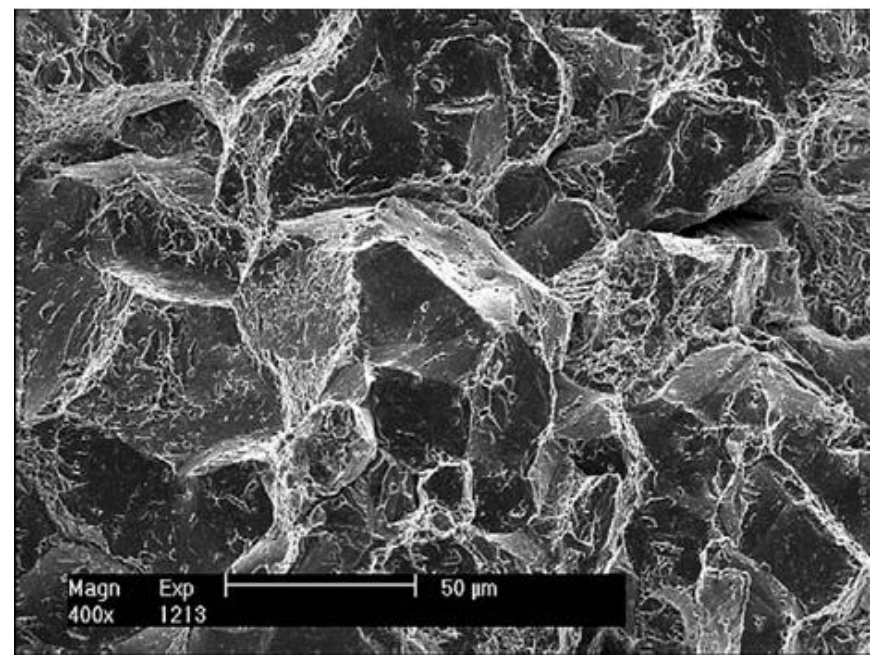

Figure 6 SEM image on breakage surface shows intergranular character

\subsection{Hardness}

The core surface and the macrodurality (HRC) of the bolt core were measured. Table 1 shows the average values of five readings. It can be seen that the core hardness is within the specified range, but the hardness of the cemented layer from the outer surface is lower than the specified one.

Table 1. Surface and core hardness (average of five readings)

\begin{tabular}{lcc}
\hline \multicolumn{1}{c}{ Hardness } & Measured value & Specified value \\
\hline $\begin{array}{l}\text { External Surface Microdurpose } \\
\text { (HRC) }\end{array}$ & 51,0 & $57-64$ \\
\hline Core Macrodurity (HRC) & 41,0 & $28-43$ \\
\hline
\end{tabular}

\section{4 .Microstructure}

Transverse microstructures from different areas were observed with SEM. The results show that the microstructure of the hardened trough in the outer region is composed of tiled martensite quality. Fine needle martensite is typical of a high carbon level as shown in Figure 7. This suggests a low carbon content in the cementitious layer, which corresponds to the hardness of the.

The base region is composed of martensite in the form of tiles, bainite, and a small amount of intergranular ferrite as seen in Figure 8. The microstructure in the region of the hole surface is shown in Figure 9. It can be seen that there is a completely decolorized layer, about $0.02 \mathrm{~mm}$, composed of ferrite and beneath it was a half-decoloured layer of about $0.50 \mathrm{~mm}$, composed of intergranular ferrite and bainite. It is also noticed that the layers from the outer surface as well as from the inside of the bolt have been decarburized.

\subsection{Depth of dew point}

In order to determine the depth of the hardened layer in the internal hole regions and the outer circle of the destroyed bolt, the hardness profiles at various surface-to-interior locations were performed (locations near and far from the fracture were selected), as observed in Figure 10. The results show that the depth of the hardened layer in the outer circle region is $0.5-0.8 \mathrm{~mm}$, being higher than the specified upper limit $(0.8-1.2 \mathrm{~mm})$, despite the hardness of the lower layer. 


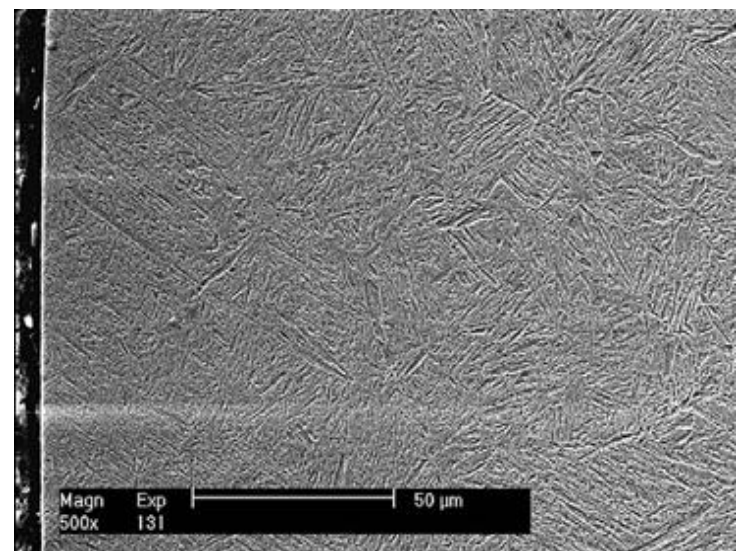

Figure 7. The microstructure of the cemented layer from the outside of the bolt (cylindrical surface)

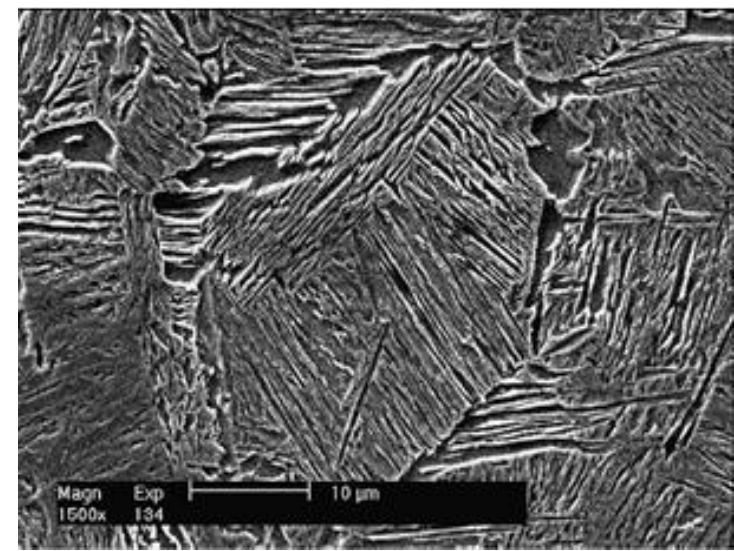

Figure 8. Microstructure of the core region

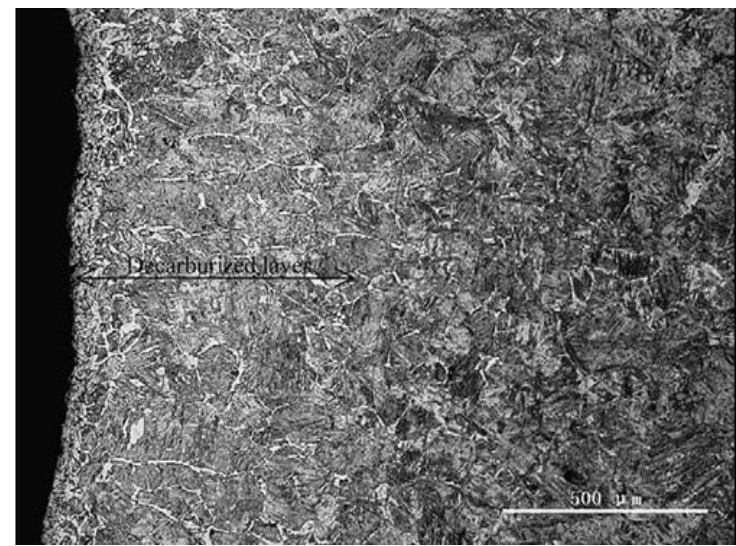

Figure 9. The microstructure of the hole surface area, with the emphasis on the decarburized layer

\subsection{Chemical composition of bolt material}

Table 2 shows the chemical composition of the bolt material compared to the specified chemical composition. It can be seen that in our case, the chemical composition of the destroyed bolt material is in the specified range. 
Volume 1, Issue 1, 2019

ISSN: 2668-0416

Thoth Publishing House

Table 2. Chemical composition of the material

\begin{tabular}{cccccccc}
\hline Elements & $\mathrm{C}$ & $\mathrm{Si}$ & $\mathrm{Cr}$ & $\mathrm{Mn}$ & $\mathrm{S}$ & $\mathrm{P}$ & $\mathrm{Fe}$ \\
\hline Analyzed & 0,2 & 0,28 & 0,92 & 0,58 & 0,014 & 0,012 & $\begin{array}{c}\text { Ponderation } \\
\text { raţie }\end{array}$ \\
\hline
\end{tabular}

\subsection{Initiation and propagation of the longitudinal crack}

From the observations and examinations presented in section 3, it is deduced that the bolt material has a chemical composition and core macrodursion within the range given by the technical specification. No obvious metallurgical defects were observed in the regions of origin of the cracks. Although the depth of the cemented and hardened layer from the outside of the nozzle is higher than specified, and the surface hardness value is slightly lower than the specified thickness, there is no evidence to indicate that the above defects lead to bolt destruction.

The bolt conveys the compressive force produced when the piston descends to the crankshaft and, by means of the stem, causes the engine to explode. In this process, the bolt and leg of the bead form a coupling. The longitudinal and transverse aspect of the cracks in the destroyed barrel, whose initiation and propagation modes differed from the value of the contact tension between the bolt and the rod leg, respectively the shoulder of the piston.

3.1.7. Initiating and propagating the longitudinal crack

The bolt tension scheme, when the external surface of the bolt presses a compressive force, is shown in Figure 11. In the Diesel engine operating state, there are compressive stresses under the outer surface of the bolt. The compressive force reaches the maximum when self-ignition occurs. At the same time, under the surface of the hole there are maximum tensions as shown in Figure 11, point.

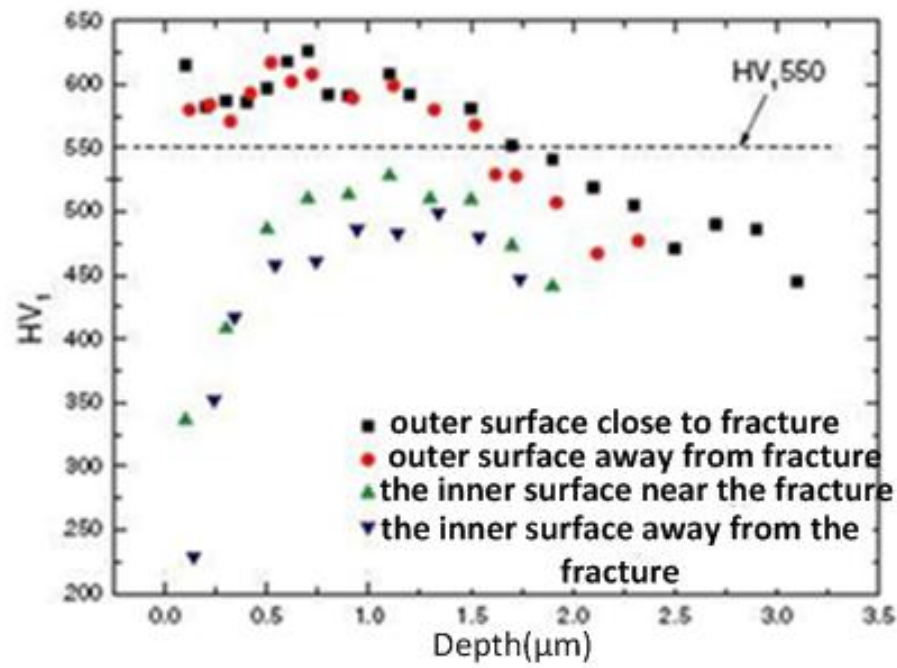

Figure 10. The profile of microdurality in different areas

When the piston moves in the reverse direction, the voltage in $\mathrm{P}$ decreases. In conclusion, in the area around $\mathrm{P}$, under the surface of the hole there are variable loads throughout the engine running. The presence of the deformed layer in the area of the hole surface makes the fatigue strength to decrease intensively, so the fatigue cracks can easily be initiated here.

The contact between the leg leg and the bolt may be considered to be approximately linear. Cracks have been initiated at different positions with the same axial orientation on the surface of the hole $(\mathrm{G}$, $\mathrm{B}, \mathrm{E}$ and $\mathrm{D}, \mathrm{A}, \mathrm{F})$. These cracks could easily propagate under traction actions and thus converge into longitudinal cracks. 


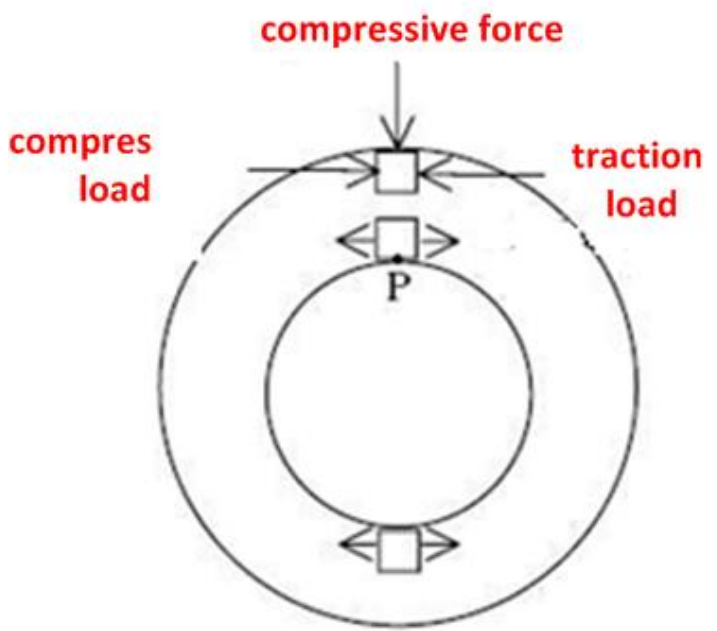

Figure 11. Tensions that occur when the bolt is pressed

\subsubsection{Transverse crack initiation and propagation}

Since the length of the bolt is greater than the width of the stem leg, it is subjected to incineration during engine operation. The origin of the crack $\mathrm{C}$ is at the intersection of the base of the bolt and the stem leg, which is the position with maximum tangential tension. On the inner surface of the bolt there is a transition threshold, which produces a concentration of tension. Inadequate chafing technology is responsible for defusing the internal surface of the bolt.

\section{Conclusions}

- The hardness of the outer surface of the bolt is less than that specified in the specification, but the depth of the cemented layer and heat treated is $0.5-0.8 \mathrm{~mm}$, higher than the upper limit of the specification. A decoupled layer of approx. $0.5 \mathrm{~mm}$ occurs in the region of the inner surface of the bolt. Carburation technology is faulty, especially inside the bolt;

- The bolt broke in a few fragments. Crack has been produced in the transverse and longitudinal directions. The crack began on the surface of the hole and then propagated outward. Fatigue breaking is the dominant yield mechanism;

- The presence of the deformed layer in the region of the bolt hole surface causes fatigue resistance to decrease in this area so that cracks have been initiated in several positions on the surface of the bore. This led to the fatigue of the bolt;

- A suitable cementitious technology must be provided to prevent decarburization and to obtain the appropriate depth of the cementitious layer so as to increase fatigue strength in the internal surface area of .

\section{References}

[1] Monika O., Peter P.,MilanU.,Fracture mechanism differences created by fatigue and impact test, Materialstoday Proceedings, vol. 4/issue 3, pp 5921-5924, 2017

[2] Zhao-Ling W, Heng X,Direct modeling of multi-axial fatigue failure for metals, International Journal of Solids and Structures, pp 216-231, 2017

[3] Pavel, A., Siguranţa în funcţionarea utilajelor petrochimice, Editura Tehnică, vol 3, pp 5-365, 1988

[4] Armando L., Rama I., José A., Carlos A., Branco G., Fatigue behaviour of $T$ welded joints rehabilitated by tungsten inert gas and plasma dressig, Materials and Design, vol 32, pp 4705-4713, 2011 